\title{
ERECTILE RESPONSE TO INTRACAVERNOUS INJECTION OF VASOACTIVE DRUGS AFTER PENILE PROSTHESIS REMOVAL
}

\author{
CHRISTIAN GEORG STIEF, M.D. \\ HELLMU'T GALL, M.D. \\ WOLFGANG SCHERB, M.D. \\ WOLFGANG BÄHREN, M.D.
}

From the BWK Ulm, Academic Hospital of the University of Ulm, Ulm, West Germany

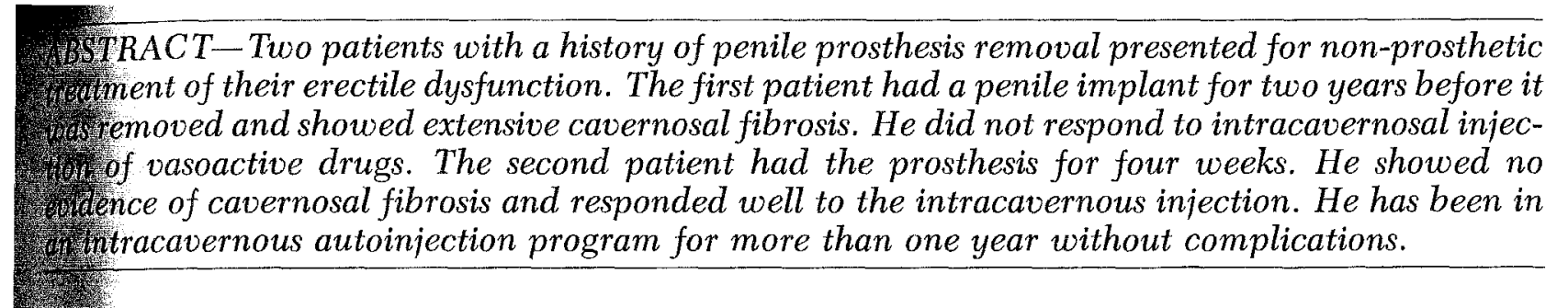

Wher some attempts to do penile venous surgery 17the beginning of the twentieth century, ${ }^{1,2}$ in2. Hition of penile prosthesis became the first efW. Wt ve treatment for organogenic erectile dys1017tion. ${ }^{3.4}$ Starting from various surgical 4. 1) Troaches, the implantation of a semirigid ${ }^{4}$ or 17. -1.9.6. the cavernous bodies and dilatation to 7.7ke room for the implant.

4. Ite most frequent complications of the Jonas 10sthesis are infection, protrusion, and severe 4. $014^{5,6}$ These complications usually require re7ival of the implant. If the patient refuses a 7o prosthetic implant, the therapeutic options 4. 17reat the erectile dysfunction are limited.

Case Reports

V.t. 1 fort

orty-six-year-old man with insulin-de1erdent diabetes had a Jonas prosthesis im1) danted for twenty-five months. He did well Wh1 1 he presented with an extrusion of the left Tosthesis through his urethral meatus (Fig. 1). Whe right and left prostheses were removed.

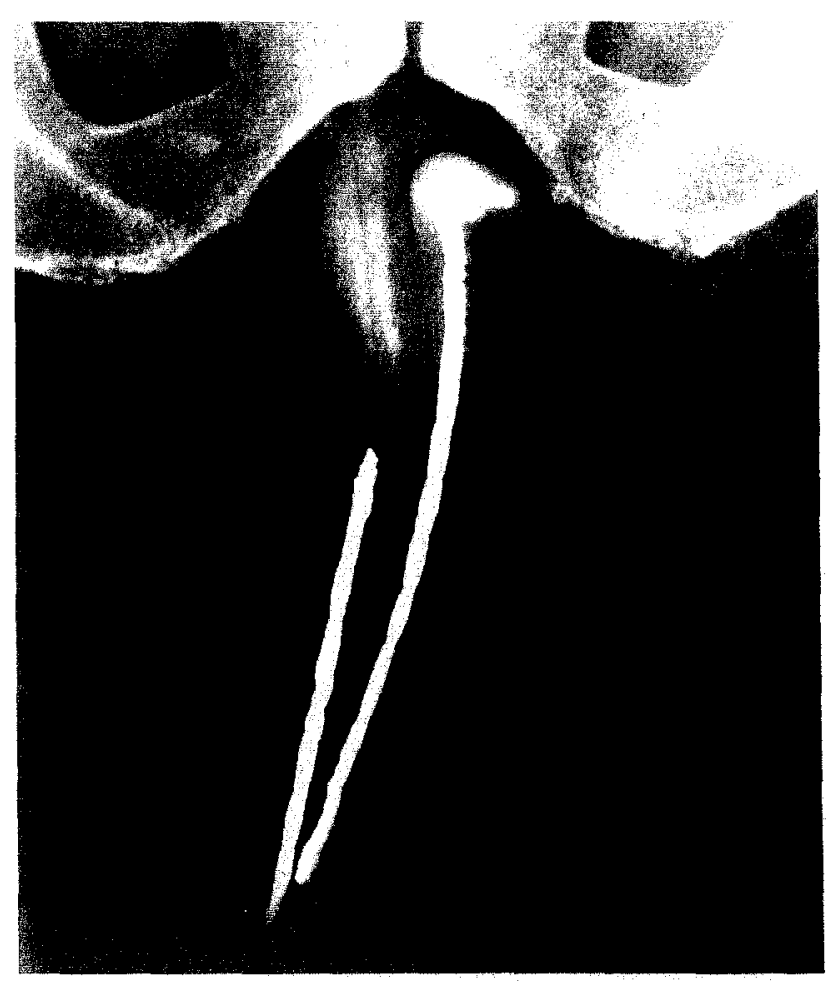

FIGURE 1. Plain $x$-ray film of Jonas prosthesis with left prosthesis protruding through meatus (Case 1). 


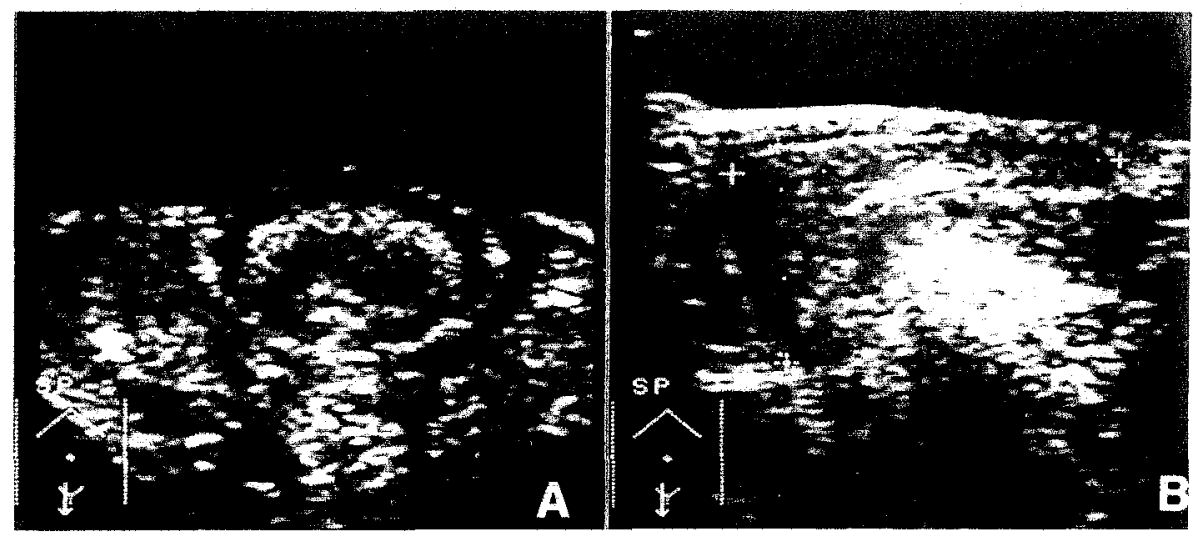

Frgure 2. Penile ultrasouth with 5 MHz-probe shows twit. cal signs of cavernous fir (Case 1). (A) Transverse sto tion; (B) longitudinal sectivith

Both sites healed well without any signs of residual infection. He reported complete loss of spontaneous erection and requested treatment for his impotence, but refused a new prosthetic implant. On palpation his penis felt hardened. Penile ultrasound showed signs of cavernosal fibrosis (Fig. 2A and B). ${ }^{7}$ Nocturnal penile tumescence (NPT)-measurements with a Jonas Snap-Gauge did not show any increase in tumescence during sleep. He showed no reaction to diagnostic intracavernous injections, even not to high doses of papaverine $(45 \mathrm{mg})$ and phentolamine $(1.5 \mathrm{mg}) .{ }^{8}$ Cavernosography was done. The insertion of the 19-G needle was difficult and the injection of contrast medium had to be performed at a high pressure $(>200 \mathrm{~cm}$ $\mathrm{H}_{2} \mathrm{O}$ ), because of the extensive fibrosis. The $\mathrm{x}$ ray films showed a shrunken and irregularly filled cavernous body (Fig. 3A and B). No remarkable increase in size of the penis was noted during the perfusion.
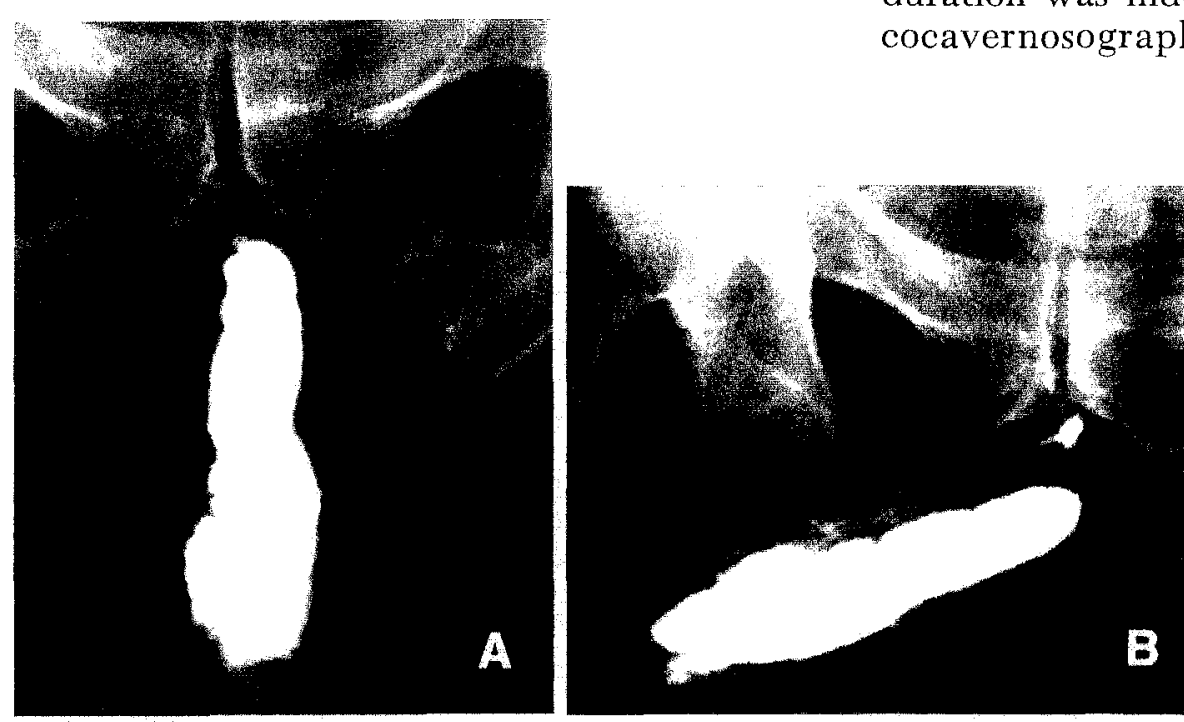

Figure 3. Cavernosograph of Case 1 shows irregitit filled and shrunken cormt cavernosum in (A) anterlor. posterior view and $(B)$ obligy? view. 

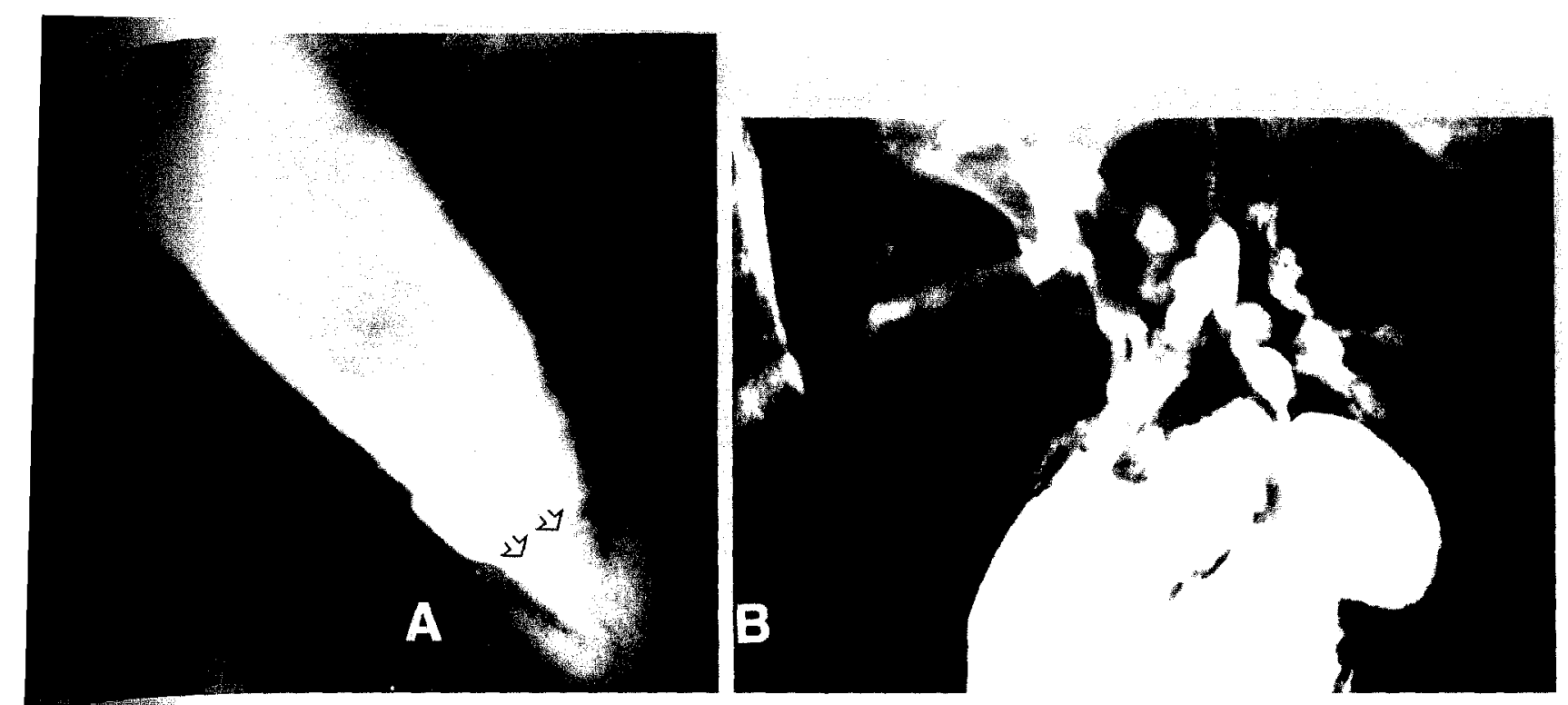

4. Cavernosography of Case 2. (A) Distal part of penis with communication between corpus -6) erriosum and glans (arrows). (B) Proximal part of penis with opacification of abnormal draining veins. Y.t.

(1)

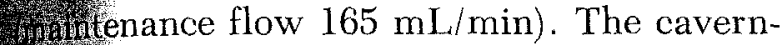
6. 5odies were of normal shape (Fig. $4 \mathrm{~A}$ and 18. 4. 0 ectile dysfunction. ${ }^{10}$ After more that fifty auWinections and no complications, he is fully 4. Itisfied with this therapy.

-3.t.

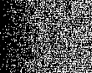

\section{Comment}

6. Whe intracavernosal insertion of a penile Trosthesis requires dilatation of the cavernous 1606. This procedure does not imply complete destriction of the cavernous tissue in all cases. 14.71) of our patients with penile prosthesis re-1004. an additional natural increase in tumes- Ex tee by sexual stimulation. Further studies -48 6 to show if the compression of the cavern2618 tissue by the penile prosthesis causes 2. adounosal fibrosis in the long run.

- We think that after removal of a penile pros2. Thesis every patient should undergo evaluation 4. He remaining erectile capacity. If he re64 (16) well to the intracavernous injection of 4. Woative drugs and he fits into the preselec20 Thiteria of an autoinjection program, he 7. howld be offered this therapeutic option.

\section{Department of Urology \\ Medical School, MHH \\ D-3000 Hannover 61, West Germany}

(DR. STIEF)

\section{References}

1. Wooten GS: Ligation of the dorsal vein of the penis as a cure for atonic impotence, Tex Med J 18: 325 (1902-1903).

2. Lowsley OS, and Bray JL: The surgical relief of impotence: further experiences with a new operative procedure, JAMA 107: 2029 (1936).

3. Scott FB, Bradley WE, and Timm GW: Management of erectile impotence. Use of implantable inflating prosthesis, Urology 2: 80 (1973).

4. Small MP, Carrion HM, and Gordon JA: Small-Carrion penile prosthesis: new implant for management of impotence, Urology 5: 479 (1975)

5. Jonas U: Five years' experience with the Silicon-Silver penile prosthesis, World I Urol 1: 251 (1983).

6. Benson RC, Barret DM, and Patterson DE: The Jonas prosthesis-technical considerations and results, J Urol 130: 920 (1983).

7. Hamm B, Friedrich $M$, and Kelami A: Ultrasound imaging in Peyronie disease, Urology 28: 210 (1986).

8. Stief CG, Bachren W, Scherb W, and Gall H: Functional evaluation of penile hemodynamics, J Urol 139: 734 (1988).

9. Lue TF, Hricak H, Schmidt RA, and Tanagho EA: Functional evaluation of penile veins by cavernosography in papaverine-induced erection, J Urol 135: 479 (1986).

10. Zorgniotti AW, and Lefleur RS: Auto-injection of the corpus cavernosum with a vasoactive drug combination for vasculogenic impotence, J Urol 133: 39 (1985). 